\title{
Ficção como jogo: reavaliando a relação entre jogos, jogar e ficção ${ }^{1}$
}

\section{Sebastian Deterding}

Doutor; University of York, York, Reino Unido

sebastian@codingconduct.cc

Tradução: Breno Maciel Souza Reis

Universidade Federal do Rio Grande do Sul, Porto Alegre, RS, Brasil

brenomaciel@gmail.com

Tradução: Suely Fragoso

Universidade Federal do Rio Grande do Sul, Porto Alegre, RS, Brasil

suelyfragoso@ufrgs.br

Revisão de tradução: Luiza Santos

Universidade Federal do Rio Grande do Sul, Porto Alegre, RS, Brasil

luizacdsantos@gmail.com

\section{Resumo}

Os game studies há muito tempo vêm debatendo como relacionar os elementos ficcionais e os do jogo nos videogames. Este artigo propõe que muitos dos desafios conceituais nesse debate podem ser solucionados se os jogos e a ficção não forem tratados separadamente, mas como formalizações específicas de um mesmo fenômeno comum: o jogar. $\mathrm{O}$ artigo apresenta cinco propostas teóricas dessa perspectiva de jogo-e-ficçãocomo-jogar (JEFCJ), segundo a qual tanto os jogos quanto a fiç̧ão apresentam mais semelhanças que diferenças. Ele extrai os princípios e vantagens compartilhadas por essa abordagem JEFCJ, e como isso ajuda a explicar tanto os pontos em comum, quanto as diferenças entre a ficção e os jogos.

\section{Palavras-chave}

Jogos. Jogar. Ficção. Pragmática. Enquadramentos.

\footnotetext{
${ }^{1} \mathrm{O}$ autor agradece a Espen Aarseth, Gordon Calleja, Sebastian Ostritsch, Jan-Noël Thon, e a um parecerista anônimo pelos comentários em versões anteriores das ideias apresentadas no artigo, e a Felix Schröter pela ajuda com o estado-da-arte da pesquisa em psicologia do desenvolvimento.
} 


\section{Introdução}

Dizer que a finalidade deste artigo é propor um "retorno a Huizinga" é mais que um apelo retórico à autoridade. A poesia nasceu do jogo (HUIZINGA, 2001, p. 125) - em princípio, esta é a posição que eu gostaria de validar aqui, se me for concedida licença artística para tomar a poesia como metonímia da ficção. Sugiro reavaliarmos a relação entre "jogo" e "ficção" nos videogames e espero demonstrar que conceber a ambos como pertencentes à categoria mais ampla do "jogar" 2 constitui uma abordagem teórica frutífera.

Certamente, a ideia de que jogos são uma subcategoria do jogar está longe de ser nova. Em Regras do Jogo, Salen e Zimmerman (2012) consideram os dois termos potencialmente contidos um no outro, conforme nosso principal interesse cognitivo: podemos pensar no jogar como um aspecto específico dos jogos (ou seja, a experiência e a prática de jogar um jogo - em contraste, por exemplo, com as mecânicas ou o papel cultural do jogo), ou podemos pensar nos jogos como um subconjunto mais formalizado do jogar. Salen e Zimmerman desenvolvem este último aspecto acrescentando que gameplay 3 é realmente o conjunto de comportamentos mais controlado e bem delimitado em um arranjo em três camadas, que consistiria de:

a) "ser brincalhão", como a mais ampla e mais vaga categoria (mais ou menos coincidindo com a categoria conhecida como "atitude lusória"4 [ibid.: 99-101]),

b) "atividade lúdica" como um grupo de atividades menor e mais formalizado que o anterior, e

c) "gameplay" propriamente dito.

A formalização, explicitação de regras e disputa por um objetivo pré-definido aparecem como a differentia specifica ${ }^{5}$ de jogos a serem jogados (SALEN; ZIMMERMAN, 2012).

No que diz respeito à origem da ficção no jogar, a noção poderia ser traçada, de forma alternativa, a partir de Huizinga (2000), da Escola de Antropologia de Cambridge (SCHECHNER, 2003), ou de Friedrich Schiller, na obra Educação Estética do Homem (1989).

\footnotetext{
2 Nota dos Tradutores: o autor utiliza a palavra "play" em sentido amplo, com a associação a diversas atividades lúdicas que lhe é própria na língua inglesa. A palavra mais próxima em língua portuguesa seria "brincar", mas esta também não tem a mesma polissemia (não abrange, por exemplo, tocar um instrumento, que também é "play"). Na impossibilidade de uma tradução suficientemente abrangente, optamos pela mais comum, embora mais restrita, que é "jogar".

${ }^{3}$ No artigo originalmente escrito em inglês, a grafia do termo encontra-se separada ("game play").

${ }^{4}$ Nota dos Tradutores: "lusório" é um adjetivo que faz referência a tudo que se relaciona com jogos em geral, ou que tem característica de jogo ou brinquedo.

5 Em latim no original.
} 
O presente artigo evoca cinco proponentes de teorias da ficção-como-jogar - todas elas figuras estimadas em seus respectivos campos. Portanto, se as noções de jogo-como-jogar (JCJ) e ficção-como-jogar (FCJ) não são totalmente novas, qual é a novidade da abordagem jogos-e-ficção-como-jogar (JEFCJ) aqui apresentada? A resposta está no "e" entre jogos-eficção, uma visão conjuntiva de ambos JCJ e FCJ ao mesmo tempo.

Este artigo argumenta que perceber o jogar como um espaço compartilhado oferece inúmeras vantagens teóricas ao pensamento atual nos game studies. De outro modo, esse artigo avança na contramão das principais tendências contemporâneas nos game studies, perguntando não o que torna os videogames específicos, mas, ao invés, o que os une a outras práticas humanas. Argumenta-se que, tanto as mídias ficcionais quanto os jogos, são refinados descendentes socioculturais das formas de jogar encontradas nos animais e nas crianças; e que compartilham uma convenção pragmática psicossocial com outras práticas derivadas do jogar (como os esportes e o ritual), as quais são atribuídos significados e desempenho, associado a uma liberdade limitada, que torna as suas consequências nulas ou "negociáveis", e transforma as suas ocorrências em "faz de conta".

Vou desdobrar este argumento em três etapas. Primeiro, vou apresentar as posições majoritárias sobre a relação entre jogos e ficção nos game studies. Na segunda etapa, vou brevemente delinear o que acredito serem os cinco principais proponentes de uma teoria FCJ - em ordem cronológica, Johan Huizinga, Gregory Bateson, Erving Goffman, Kendall Walton e, mais recentemente, Brian Boyd - e sintetizar os princípios que compartilham.

Em uma terceira e final etapa, vou rascunhar as principais vantagens da abordagem JEFCJ em comparação com o pensamento atual sobre jogos e ficção em videogames: contrapor o excepcionalismo latente e o essencialismo dos game studies; permitir uma melhor abordagem das semelhanças e diferenças entre jogos e outras práticas como artes, rituais ou esportes; discutir a liberdade pragmática comum aos jogos e à ficção de serem algo "sem consequência"; discutir a qualidade experiencial e semântica do "faz-deconta"; fornecer uma explicação funcional, ontogênica, filogenética e situacional para tal liberdade e qualidade; e, finalmente, fornecer parâmetros para uma história evolutiva e cultural do jogar, dos jogos e ficção.

Antes de começar, algumas observações: em primeiro lugar, vou utilizar uma interpretação bastante livre da tríade linguística da sintaxe, semântica e pragmática como estrutura organizadora das ideias neste artigo. Aqui, "sintaxe" se refere às propriedades 
formais e materiais e às estruturas do meio semiótico; "semântica" à forma e significado na forma lógica ou propositiva; e "pragmática" aos usos e posições do meio na vida cotidiana. "Experiência" é por vezes utilizada para denotar a qualidade experiencial, fenomenológica, de perceber e interagir com certo meio, em contraste à lógica semântica, mais restritiva, de forma e conteúdo.

Em segundo lugar, ainda que a diferença linguística entre jogar e jogo não esteja presente em todas as línguas, faço uma clara separação entre a forma livre "jogar", prototipicamente presente entre animais ou na brincadeira de crianças, e o "jogo" definido por regras, mais formalizado e refinado culturalmente, por exemplo os jogos de tabuleiro ou cartas. Utilizarei os dois termos com estes significados ao longo de todo o texto.

Em terceiro lugar, não tenho a intenção de ressuscitar o zumbi "ludologia/narratologia". Considero este debate como sendo do interesse apenas de futuros historiadores da ciência que desejarem estudar como esse "fratricídio" serviu como um mito de fundação necessário para a disciplina. Além disso, de alguma forma, era um argumento que girava em torno da narratividade de videogames - se eles eram estruturados como uma narração (ou não), e se a 'tematização' ou se a vinculação das regras do jogo à narrativa é um componente necessário para a experiência, análise ou definição dos jogos. Desde o início, "ficção" nunca foi realmente parte desse debate (AARSETH, 1997), e, é necessário repetir que, ainda que às vezes sejam colocados como equivalentes, "ficção" e "narração" são dois conceitos bastante diferentes (RYAN, 2008).

Colocando de forma clara, "narração" refere-se a "contar uma história". É relativo a:

a) uma certa qualidade sintática, formal, da comunicação, a qual podemos chamar de "narratividade" (estar organizado e apresentado de forma que poderíamos reconhecer como "típicas" para histórias);

b) um certo tipo semântico de afirmativa (uma sequência temporal de eventos), e;

c) uma certa situação comunicativa pragmática, explícita ou implícita (que consiste de um narrador relatando uma história para um receptor).

"Ficção", por outro lado, se refere à verdade peculiar ou ao status de realidade de certas ações e comunicações - com frequência, ainda que não necessariamente, de ações e comunicações relatadas em uma narração. Novamente, podemos diferenciar:

a) uma dimensão sintática, "ficcionalidade" ("sinais de ficcionalidade"), propriedades formais que nos permitem separar, digamos, um filme de ficção de um documentário; 
b) uma dimensão semântica, usualmente chamada de "fictividade6" (o estatuto lógico ou ontológico das proposições expressas em uma obra de ficção), e;

c) uma base pragmática situacional, que situa o discurso ficcional no cotidiano.

Nas próximas páginas, usarei esses termos da forma como estão postos aqui e usarei "mídias ficcionais" para me referir a textos, filmes, quadrinhos, peças de teatro, etc., que apresentam eventos fictivos em uma forma ficcional.

Então, para reiterar, esse artigo é sobre ficção, não narração; e também, desconsidera, em grande parte, as dimensões sintática e semântica. Não estou interessado nem nas estruturas narrativas ou ficcionais dos jogos, nem no "estatuto lógico do discurso ficcional" em jogos, parafraseando Searle (1975). Ao invés disso, o meu interesse aqui é $a$ pragmática e a experiência compartilhadas de jogo e fiç̧ão.

\section{A relação entre jogo e ficção nos game studies contemporâneos}

Se pensarmos jogo e ficção como categorias possíveis de representar em diagramas de Venn, encontramos quatro relações possíveis:

a) jogo contém ficção;

b) ficção contém jogo;

c) ficção e jogo são separados, sem (necessariamente) se sobrepor;

d) ficção e jogo (necessariamente) se sobrepõem.

Apenas as possibilidades 3 e 4 foram realmente propostas no campo dos game studies. A primeira posição - jogos, de alguma forma, "contêm" ficção - pode ser associada com Escolas de Literatura do Modernismo tardio, como a OULIPO francesa, mas está ausente nos game studies. É possível pensar que a posição 2 - ficção "contém" jogos - é mais presente, uma vez que transparece em expressões como "ficção interativa", "narrativa interativa" ou "teatro virtual". Tais frases apontam para a noção de que videogames são, basicamente, expressões da mídia ficcional tradicional como a literatura ou o cinema, apenas com algo "adicionado" - esse algo sendo "interatividade", "simulação", "proceduralidade", "ergodicidade" ou coisa que o valha. No entanto, como mostram as leituras críticas do debate ludologia/narratologia (FRASCA, 2003), essa posição

${ }^{6}$ Nota dos Tradutores: no original, "fictiveness". 
"extensionista" é, na verdade, mais uma teoria popular e um erro de leitura forçado por certos autores do que uma posição séria proposta por algum acadêmico.

A noção de que ficção e jogos são separados - chamemos de posição "separatista" foi proposta, entre outros, por Espen Aarseth. Em seu artigo "Doors and Perception: Fiction vs. Simulation in Games" (2007), Aarseth tenta desatar a relação de jogo e ficção em videogames introduzindo outra categoria, o "virtual" ou "simulado". Ele afirma que as simulações são novidades específicas dos videogames e que são "ontologicamente diferentes" de entidades reais ou ficcionais, uma vez que "nós respondemos diferentemente a elas, elas são construídas de forma diferente e as trocas sociais das quais elas fazem parte são diferentes dos usos sociais da ficção" (AARSETH, 2007). "Ficção" nos termos de Aarseth, corresponde a signos representando entidades fictivas, e jogos frequentemente contêm várias delas. "Simulação", por outro lado, se relaciona a um elemento no qual se pode "agir", dado que se trata de "um modelo dinâmico que irá especificar seu comportamento e responder a um input" (AARSETH, 2007). Seu exemplo é uma porta que um personagem pode manipular (simulação) versus uma porta que é meramente parte das texturas de fundo (ficção). Nessa lógica, para cada elemento dentro de um videogame, é possível dizer se ele pertence ao grupo de elementos de "simulação" ou ao grupo de elementos de "ficção". Ou seja, nós podemos separar claramente a parte "jogo" e a parte "ficção" em qualquer videogame.

A quarta posição - a de que categorias de jogo e ficção de certa forma se sobrepõem em videogames - foi expressa da forma mais articulada por Jesper Juul, em seu influente Half-real (2005): "um videogame é tanto um conjunto de regras quanto um mundo ficcional"7 (JUUL, 2005, p. 1). Segundo Juul, essa convergência de regras e ficção nos videogames não é acidental, mas uma dinâmica importante para a experiência dos jogos: "a ficção leva o jogador à compreensão das regras, e as regras levam o jogador a imaginar um mundo ficcional" (JUUL, 2005, p. 197, ). Mundos ficcionais de videogames tendem a ser "incoerentes" devido às demandas das regras, que produzem elementos ou eventos que não se integram facilmente ao mundo ficcional (JUUL, 2005). 0 autor aponta também que essa qualidade de game-e-ficção "meio-real" diferencia os videogames de outros jogos: "tendo mundos ficcionais, os videogames se afastam dos jogos tradicionais, não-eletrônicos, que

\footnotetext{
${ }^{7}$ Note-se que Juul equaciona o debate narratologia/ludologia sobre os games 'serem' ou 'conterem' narração com a questão de eles 'serem' ou 'conterem' ficção: “o principal argumento deste livro, que videogames são regras e ficção, é uma resposta a uma longa história de discussões se os games são um ou outro" (Juul, 2005, p. 12).
} 
são predominantemente abstratos, e isso é parte da novidade dos videogames" (JUUL, 2005, p. 1).

Embora eu basicamente concorde com as posições de Aarseth e Juul - há uma diferença entre texturas de fundo e elementos de jogo maleáveis, orientados por regras, e videogames atuais frequentemente apresentam mundos ficcionais audiovisualmente mais exuberantes que os tradicionais jogos de tabuleiro -, também vejo falhas em suas posições, uma vez que ambas partem de uma separação inicial entre jogo e ficção, para depois recombiná-los nos videogames. Como veremos, no nível pragmático e experiencial, o jogar de qualquer jogo (e entre eles, os videogames) já é sempre tão ficcional como os eventos relatados em um romance, assim como os indicativos dos mundos imaginários (ou sua incoerência) não são novidade ou especificidade dos videogames - também existindo em jogos mais tradicionais, assim como em romances, filmes ou peças de teatro. Voltando a nossos diagramas de Venn, essa noção pode ser expressa desenhando-se um terceiro círculo ao redor das categorias de "jogo" e "ficção". Defendo que esse círculo, que contém tanto jogos quanto mídias ficcionais, corresponde ao "jogar".

\section{Ficção como jogar: cinco teóricos}

A maior parte dos acadêmicos de game studies concordará imediatamente com Salen e Zimmerman (2012) que jogos podem ser compreendidos como uma subcategoria do jogar. A parte de uma abordagem JEFCJque não é aceita tão prontamente (em game studies tanto quanto em estudos literários, de mídia ou filosofia) é a da ficção-como-jogar. Assim, a primeira tarefa desse artigo parece ser fornecer a devida consistência e plausibilidade à FCJ. Para tanto, evocarei os principais defensores desse ponto de vista e pontuarei sua vasta congruência, tanto entre si quanto com o estado atual da etologia, antropologia, psicologia evolucionária e do desenvolvimento.

\subsection{Johan Huizinga}

Pressuponho que os leitores deste artigo estarão familiarizados com a definição de jogar de Huizinga e, portanto, passarei ao largo dela e favorecerei certos aspectos menos conhecidos que são relevantes aqui. Ainda que a evidência empírica sobre a qual Homo 
ludens é construído esteja obviamente datada e, com frequência, obsoleta, sua premissa teórica geral do "jogar como elemento da cultura" ainda se mantém. Huizinga observa que jogar é um fenômeno pré-humano e, de fato, desde o berço da cultura humana, no comportamento animal, o jogar proporciona a transcendência de meros reflexos para criatividade e significados (HUIZINGA, 2001) ${ }^{8}$. Nem toda arte é fundada no jogar, mas as artes "musicais" (incluindo literatura e drama) e "[...] a maneira como elas [todas as artes] são recebidas pelo meio social" são jogar, do início ao fim (HUIZINGA, 2001, p. 188). Jogar contém uma combinação peculiar de repetição e variação; estimula a imaginação e captura a atenção (HUIZINGA, 2001, p. 10, 4, 2). Seu contraste frente ao resto da vida cotidiana é social, "[...] previamente delimitado, de maneira material ou imaginária, deliberada ou espontânea" (HUIZINGA, 2001, p. 13). Jogar é atrelado com ritual (religioso), a ponto de tornarem-se quase indistinguíveis. Sendo o jogar a origem do ritual, também fluem do jogar a arte, a ciência e a ordem social (HUIZINGA, 2001).

\subsection{Gregory Bateson}

Observando lontras e macacos jogarem em um zoológico de São Francisco no início da década de 1950, Bateson observou que, do mesmo modo que entre os humanos, a comunicação entre os animais tem lugar em diversos níveis ao mesmo tempo. Existe um conjunto de regras meta-comunicacionais, sobre como a comunicação se relaciona ao que é denotado. Bateson chama esse conjunto de regras meta-comunicacionais de "contextos" ou "enquadramentos" (frames) e aponta o jogar como seu protótipo por excelência: um mordiscar de brincadeira comunica que tal ato não se trata de uma mordida de fato, mas deve ser interpretado 'como se fosse' uma mordida. De fato, para Bateson, o jogar seria possivelmente a origem da comunicação simbólica: "a evolução do jogar pode ter sido um passo importante na evolução da comunicação" (BATESON, 2000, p. 181, ).

Enquadramentos são estabelecidos por mensagens meta-comunicativas (majoritariamente implícitas), como a mensagem "isso é brincadeira" implícita no mordiscar ao invés do morder. Tais mensagens "enquadradas" definem quais mensagens pertencem e quais não pertencem a um dado enquadramento. Elas também definem "premissas"

\footnotetext{
8 A versão citada originalmente é de 1955, em inglês. Utilizamos aqui os trechos traduzidos de acordo com a versão em português de 2001 - portanto, as referências aos números de página são relativas a esta última, e não à edição consultada pelo autor.
} 
(BATESON, 2000, p. 187) sobre como interpretar as mensagens pertencentes ao enquadramento. Bateson enfatiza que os enquadramentos e as meta-comunicações não são, em si, comunicações - elas pertencem a um nível lógico diferente. "Jogar não é o nome de um ato ou ação; é o nome de um enquadramento para ação" (BATESON, 1979, p. 139, grifos do autor, ). Essa é sua maior objeção ao Homo ludens: a 'definição' de jogar de Huizinga, segundo a crítica de Bateson, mistura o nível lógico de um contexto ou categoria de atividade com o nível de atividades singulares (BATESON, 1979).

A mensagem "isso é brincadeira" é marcadamente "paradoxal" ou "subjuntiva" uma vez que significa, ao mesmo tempo, a presença e a ausência e a identidade e a nãoidentidade com a qual denota: "não apenas a mordiscada não denota o que seria denotado pela mordida que representa, mas, em adição, a mordida em si é ficcional" (BATESON, 2000, p. 182). Essa qualidade não é peculiar apenas ao jogar 'em si'. Jogar, arte, ritual, fantasia e drama "formam, juntos, um único complexo de fenômenos" (BATESON, 2000, p. 181). Todos eles compartilham da pretensa qualidade do "como se" ou "tipo um": "toda a fantasia, poesia, ballet e arte em geral deve seu significado e importância à relação à qual me refiro quando digo que a figura do cisne [no ballet Lago dos Cisnes] é 'tipo' um cisne - ou um cisne 'de faz-de-conta'” (BATESON, 2000a, p. 34).

\subsection{Ervin Goffman}

Em certa medida, o livro Quadros da Experiência Social (2012), do sociólogo Erving Goffman, é pouco mais do que a explicação sistemática e refinada dos conceitos de enquadramento de Bateson para caracterizar as realidades multidimensionais e as camadas interpretativas da vida social humana. Para concordar coletivamente "o que é que está acontecendo aqui" (GOFFMAN, 2012, p. 8) - estas pessoas em linha são um desfile militar ou um cortejo de casamento ou um carnaval ou uma performance pública ou...? - Goffman argumenta que nós nos baseamos em convenções compartilhadas e adquiridas socialmente, "enquadramentos" 9", que definem situações e organizam o que nós devemos e não devemos prestar atenção, como interpretar os eventos e como agir e reagir apropriadamente em cada

\footnotetext{
9 Nota dos Tradutores: a palavra "frame" nos textos de Goffman muitas vezes não é traduzida para o português brasileiro. No sentido utilizado pelo autor do presente artigo, consideramos a tradução para "enquadramento" adequada e optamos por adotá-la em prol da fluidez de leitura.
} 
situação. Na interação coorientada dos comportamentos e das interpretações, os participantes reconhecem, concordam e reproduzem a moldura "correta" da situação.

Enquadramentos podem agir sozinhos ou serem sobrepostos em outros enquadramentos. Goffman chama esses enquadramentos secundários de "chaves" (keys), "um conjunto de convenções pelas quais uma dada atividade, já significativa em termos de um enquadramento primário, é transformado em algo padronizado na atividade - mas visto pelos participantes como algo bastante diferenciado" (GOFFMAN, 2012, p. 43). Pistas metacomunicativas, chamadas de "suportes", delineiam as fronteiras espaço-temporais das "chaves" (pense, por exemplo, na cortina abrindo ou fechando uma peça de teatro ou na palavra "romance" na capa de um romance).

Goffman se alinha com Bateson no fato de que mesmo animais brincam, e vê este brincar como a instância significativa mais inicial do "chaveamento" (GOFFMAN, 2012, p. 40). O "faz-de-conta" - a imitação ou encenação de outra atividade que se separa de sua função e consequência usuais - é uma das chaves mais básicas, e os três tipos de faz-deconta são brincadeiras ${ }^{10}$ sociais (p. 48), "fantasiar ou sonhar acordado" (p. 52) e "roteiros dramáticos" que contém "todas as linhas da experiência pessoal disponível para participação indireta" (GOFFMAN, 2012, p.53): romances, filmes, peças de teatro, televisão, rádio, etc.

Atividades de faz-de-conta são profundamente "cativantes" (p. ex., absortivas e capazes de direcionar a atenção para uma dimensão alternativa projetada) e frequentemente organizadas em torno de objetos ou performances "cativáveis" (GOFFMAN, 2012, p. 46), projetados e utilizados com este propósito - novamente, pense no palco de um teatro ou um romance. Eles são cheios de molduras quebradas e com limites embaçados. Tais "experiências negativas" são potencialmente prazerosas e, portanto, criadas intencionalmente. Elas são acionadas pelo fato de que todos os freios dos enquadramentos permanecem dentro do enquadramento "seguro" do brincar.

\footnotetext{
10 Nota dos Tradutores: a expressão originalmente empregada pelo autor é "playfulness". Optamos pela tradução como "brincadeira" pois, de acordo com Sicart (2014, p. 21-22), "playfulness" é um termo que designa a atitude que envolve o jogar mesmo em situações nas quais não se trata, especificamente, de um jogo, envolvendo, entre outros, os encontros sociais, amorosos, etc. Enquanto que "play" pode ser utilizado para se referir à atividade ou à ação de jogar, "playfulness" está ligado à atitude necessária para que a atividade ocorra - sendo ela um jogo ou não.
} 


\subsection{Kendall Walton}

Dentro dos estudos literários e da filosofia, Mimesis as Make-Believe (1990) de Kendall Walton é indiscutivelmente a mais amplamente reconhecida teoria da FCJ - mesmo porque sua abordagem se sustenta bastante bem frente às caracterizações de ficção da dita "ciência normal". Walton sugere subordinar a literatura ficcional, o cinema, peças de teatro e pinturas à categoria de "arte representacional", que ele considera serem integralmente ficcionais. Walton resume o cerne de seu princípio da seguinte forma:

As atividades nas quais trabalhos de arte representacional estão firmados [...] são melhor vistas como um contínuo dos jogos de faz-de-conta de crianças. De fato, eu advogo a respeito destas atividades como sendo jogos de faz-de-conta elas próprias e, devo argumentar, que trabalhos de ficção representacional funcionam como adereços nesses jogos, como bonecas e ursos de pelúcia servem como adereços em brincadeiras infantis (WALTON, 1990, p.11, ).

A função de tais "adereços" é incitar, ancorar, focar e coordenar imaginações individuais e coordenadas (WALTON, 1990, p.19-21). Essa capacidade imaginativa dos adereços remonta ao que Walton chama de "princípios de geração": "regras sobre o que deve ser imaginado e em quais circunstâncias"11, baseado em certo adereço em um certo jogo de faz-de-conta (WALTON, 1990, p. 40, ). Princípios de geração são parte de uma mais ampla e compartilhada "convenção, compreensão, acordo no jogo de faz-de-conta" (WALTON, 1990, p. 38, ) que normalmente precisa ser apreendida ou acordada em um determinado momento; a convenção ou a "praticamente irresistível disposição para adquirila" (WALTON, 1990, p. 41, ) é provavelmente inata.

Ainda assim, em uma análise final, jogos de faz-de-conta se mantêm dependentes do contexto: "quais princípios de geração existem depende de quais as pessoas aceitam em contextos diversos. Os princípios que estão em vigor são aqueles que são entendidos, ao menos implicitamente, como em vigor" (WALTON, 1990, p. 38, ). A diferença entre mídia ficcional e não-ficcional, portanto, reside no reconhecimento contextual da "função social dos adereços em serviço em jogos de faz-de-conta" (WALTON, 1990, p. 69, ).

Nós usualmente nos sentimos desconfortáveis em comparar crianças brincando com adultos lendo livros, vendo pinturas ou filmes porque estes últimos são postos no papel mais restritivo de "apreciadores" ao invés de "participantes" do jogo de faz-de-conta em

11 "Rules about what is to be imagined in what circumstances". 
questão. Essa maior restrição se apresenta em dois aspectos: "existem poucos tipos de ação que podem ser realizadas de modo que seja ficcional que o espectador as realize; e ainda menos ações que o espectador pode de fato realizar que sejam facilmente interpretáveis como contribuições ao jogo" (WALTON, 1990, p. 225, ).

É curioso que Walton esteja posicionado frente a outros teóricos da FCJ apresentados aqui, uma vez que está menos interessado nas pragmáticas da ficção do que se pode imaginar. Mimesis as Make-Believe delineia seu maior impulso do projeto semântico da filosofia analítica para reincorporar aquele tipo de discurso "parasitário" (SEARLE, 1975, p. 326) que é o ficcional dentro da simplicidade da veracidade ou falsidade, proposições e discurso. Assim sendo, Walton tenta conceder às proposições uma existência ontológica independente dos sujeitos cognitivos que os imaginam através da interação de adereços e princípios de geração (WALTON, 1990, p. 38-42).

Entretanto, acredito ser possível alavancar essa perspicácia pragmática de sua teoria, a despeito do projeto semântico que lhe é subjacente. Portanto, em suma, Walton defende que a ficção - e, de fato, as artes representativas em geral - derivam da simulação do jogar infantil, e todas essas atividades de "faz-de-conta" são propiciadas por certas (provavelmente inatas) convenções sociais que são trazidas à tona em uma determinada situação. 0 "faz-de-conta" impele e organiza a imaginação compartilhada, e é um "elemento pervasivo da experiência humana, importante não apenas nas artes", mas "crucialmente envolvido também em certas práticas religiosas, [bem como] no papel dos esportes em nossa cultura" (WALTON, 1990, p. 7, ).

\subsection{Brian Boyd}

Em sintonia com a ascensão da "poética cognitiva" (STOCKWELL, 2002), "On the Origin of Stories" (2009) do estudioso literário Brian Boyd, busca nada menos do que uma abordagem evolucionária que soma a arte, a narração e a ficção. Boyd defende que a arte é melhor compreendida como "um tipo de jogo cognitivo, um conjunto de atividades com o objetivo de engajar a atenção humana através de seu apelo pela nossa preferência por informação inferencialmente rica e, consequentemente, padronizada" (BOYD, 2009, p. 89, grifos do autor, ). A vantagem adaptativa da arte é treinar nossas faculdades mentais no reconhecimento de padrões e exploração criativa de novos pensamentos e comportamentos. Boyd segue os proponentes da "cognição fundamentada" ou "incorporada", para os quais a 
racionalidade, memória e imaginação estão fundamentalmente baseada em simulações imaginativas internas de memórias de experiências multimodais e incorporadas (BOYD, 2009, p. 155).

A narração, ancorada na linguística ou em outra representação externa (tal como imagens ou reencenações), está particularmente sintonizada para instigar tais simulações multimodais de eventos e seu significado social, "estratégico" - intenções, agendas ocultas, relações sociais; assim, a narração oferece o benefício evolucionário de facilitar o compartilhamento social de experiências passadas. A ficção ou narração ficcional, por fim, promove a cooperação ao criar fortes emoções e valores compartilhados através de pseudoexperiências compartilhadas, e permite a criatividade cognitiva e comportamental ao nos permitir explorar recombinações contrafactuais da experiência (BOYD, 2009, p. 192-197). A habilidade para cativar e organizar a atenção individual e compartilhada, bem como para alternar entre a variação criativa e a repetição que induz o aprendizado é um elemento chave para as vantagens adaptativas sociais e individuais do jogo, da arte, da narrativa e da ficção (BOYD, 2009, p. 99, 184).

Tanto o jogo cognitivo da arte, narrativa e ficção quanto nossa capacidade de racionalidade simbólica e contrafactual, metacomunicação e teoria da mente (ou seja, entender outros seres como agentes conscientes, intencionais)se originam do jogo animal: "dentro do enquadramento [sic] do jogo, animais dão o passo inicial em direção à representação ou re-presentação do real que o pensamento e a linguagem permitem" (BOYD, 2009, p. 180, )

Podemos retratar essa filogenia da representação e da arte, narrativa e ficção na ontogenia da simulação do jogo infantil. Ontogeneticamente, o jogo de simulação precede a linguagem e a teoria da mente. Na primeira infância, o jogo, a narração, o drama e a ficção são uma só coisa. Boyd sintetiza o resultado dos estudos longitudinais do jogo infantil do psicólogo do desenvolvimento Keith Sawyer: "para as crianças a direção, narração e encenação fluem direta e naturalmente entre si. Desde que a história-jogo [sic] continue, a consistência do meio ou o seu modo não importam" (BOYD, 2009, p. 177, ).

A propósito, o entendimento de Boyd se encaixa perfeitamente com outras duas abordagens evolucionárias do jogo e do jogar: o recente "Cultural Theory of Gaming" (2006) de Janet Murray, e a teoria diverso-comportamental proto-cognitiva do jogo (ou teoria DCPC) de Ohler e Nieding $(2001 ; 2006)$. Ohler e Nieding começam pela explicação evolutiva do jogo de Sutton-Smith (2009) como uma "variabilidade adaptativa" ou "diversificação 
comportamental": o jogo é uma modalidade cognitiva que recombina padrões comportamentais vigentes, criando novos padrões que, potencialmente, se encaixam melhor em situações inéditas ou já existentes. A parte proto-cognitiva de sua teoria defende que, em espécies com arquitetura cognitiva evoluída - hominídeos e grandes primatas -, o módulo do jogo faz a mesma coisa para as "representações primárias" do input sensorial. Ao recombiná-las sistematicamente, permite que uma representação esteja conectada com outra, ao invés de estarem relacionadas apenas com inputs sensoriais imediatos. Representações jogadas, por consequência, podem desencadear e se referir a outras representações - que proporcionam imaginações ou "representações secundárias" desconectadas dos inputs sensoriais, bem como referências semióticas.

Em uma via ligeiramente diferente e a partir do trabalho do psicólogo do desenvolvimento Michael Tomasello, Janet Murray defende que a principal conquista evolutiva subjacente à cultura humana foi a habilidade de criar teorias da mente graças às “cenas de atenção conjunta” (MURRAY, 2006, p. 187); ou seja, participar conjuntamente da mesma coisa, sabendo que outros também participam dessa mesma coisa. As teorias da mente são a origem do pensamento de causa-e-efeito como a primeira instância do reconhecimento de causas ocultas (intenções) para fatos evidentes (comportamento). Animais e humanos são capacitados a desfrutar do jogar porque ele facilita cenas de atenção conjunta e a habilidade de se engajar nelas. Murray sugere que os jogos são originados desse momento evolutivo como um meio representacional que reforça a exploração da atenção conjunta, enquanto as histórias se originaram dele como um meio que reforça o raciocínio causal (MURRAY, 2006).

\subsection{Resumo}

Vamos recapitular em linhas gerais o quadro apresentado nas páginas anteriores: todos os autores - com a notável exceção de Kendall Walton - abordam o jogo e a ficção de um ponto de vista antropológico. Eles concordam que jogar, e mais especificamente, o fazde-conta do jogo, é pré-humano e antropologicamente universal (etologia, psicologia do desenvolvimento; e, em geral, a antropologia sustenta, isso). Ele está intimamente intrincado com os rituais e formalmente caracterizado pela díade da recombinação e repetição criativas. Ele foca, absorve e organiza as atenções, tanto individuais quanto sociais, dá indicativos para a imaginação por meio de objetos, e igualmente tem um papel 
fundamental na evolução da comunicação simbólica, da metacomunicação, da teoria da mente e, por consequência, da cultura.

Jogar com objetos, ações e comunicações confere a eles uma peculiar forma, semântica e experiência de "tipo de", "como se", "faz-de-conta". 0 antropólogo Alexander Alland (1977, p. 39) coloca isso em termos de "transformação-representação": jogar transforma-e-consequentemente-representa outro comportamento (uma mordiscada é uma leve alteração de uma mordida, tornando-se assim algo que meramente denota uma mordida). A semântica e a experiência do assim transformado-representado se altera profundamente, e talvez seja melhor compreendido pela definição de "lúdico" elaborada pelo antropólogo da religião André Droorgers (1996, p. 53): “a capacidade de lidar simultaneamente e subjuntivamente com duas ou mais formas de classificar a realidade". A mordiscada é e não é, ao mesmo tempo, uma mordida, e nós somos e não somos caubóis e índios no jogo Cowboys and Indians. Tanto o material quanto o significado, o sensível e o imaginado, o factual e o fictivo estão copresentes na experiência.

O jogo suspende temporariamente a função usual e a consequência vinculada aos comportamentos e comunicações. Nós podemos fazer e dizer coisas quando estamos jogando sem consequências, porque elas são "apenas como-se". Esse desacoplamento pragmático e semântico e essa subjuntividade experiencial são o que proporciona um espaço seguro para a recombinação criativa, "lúdica", de comportamentos, cognições e significados. A extensão do jogo - quais objetos, comunicações e ações pertencem e não pertencem a ele - é acordada situacionalmente (geralmente de forma implícita), sinalizada por pistas metacomunicativas. Entretanto, para que funcione, tais definições situacionais e meta-mensagens necessitam de algumas convenções sociais comuns que nos permitem reconhece-las, bem como saber como interpretar especificamente um fenômeno em relação à sua definição específica e meta-mensagem. Uma mordiscada de brincadeira significa algo diferente de uma mordida ameaçadora. Bateson e Goffman chamam essas convenções de "enquandramento"; já Walton, de "princípios de geração".

Finalmente, jogar é a origem filogenética e ontogenética direta ao menos da "música" (HUIZINGA, 2001) ou das artes "representacionais" (WALTON, 1990) e, assim, da ficção. Artes representacionais e, portanto, mídias ficcionais como romances, peças de teatro ou filmes, apresentam objetos e performances ('adereços', 'envolvimentos') para extrair e organizar a atenção e a imaginação compartilhadas; eles empregam uma continuidade do "enquadramento" do jogo e pistas meta-comunicacionais que definem o engajamento nos 
mesmos como sendo diferentes da vida cotidiana, ao (a) transformar-representar os eventos que se dão em eventos de "faz-de-conta", e (b) suspender sua função social e sua consequência.

\section{Vantagens da perspectiva JEFCJ para os game studies}

Por uma questão argumentativa, vamos substituir o termo "mídia ficcional" do parágrafo acima pelo termo "games" ou "videogames":

(Vídeo) games “apresentam objetos e performances ('adereços', 'envolvimentos') para extrair e organizar a atenção e a imaginação compartilhadas; eles empregam uma continuidade do "enquadramento" do jogo e pistas meta-comunicacionais que definem o engajamento nos mesmos como sendo diferentes da vida cotidiana, ao (a) transformarrepresentar os eventos que se dão em eventos de "faz-de-conta", e (b) suspender sua função social e sua consequência".

As dimensões deste artigo impedem uma comparação mais detalhada entre a atual definição de jogos e videogames da "ciência normal" (SALEN; ZIMMERMAN, 2012; JUUL, 2005). Passarei por alguns aspectos mais extensivamente nos próximos parágrafos; mas, de outro modo, confio na boa-intenção do leitor para reconhecer as semelhanças pervasivas dessa representação da ficção-como-jogo com as atuais conceitualizações dos (video)games e tirar suas próprias conclusões.

Agora, se alguém admite que essa perspectiva JEFCJ estabeleça um denominador comum para jogos e mídia ficcional, o que isso significa especificamente para videogames, e para a relação entre games e ficção em videogames? Eu consigo ver sete vantagens principais para tal abordagem: ela esvazia o excepcionalismo e evita o essencialismo das atuais definições de jogo; ela aborda as propriedades que os jogos compartilham com outras práticas performativas, de "faz-de-conta", especialmente a licença pragmática de ser 'sem consequência' e para a representação-transformação do "faz-de-conta"; e ela fornece uma explicação multidimensional coerente, bem como uma história do jogar, da ficção e dos jogos. 


\subsection{Esvaziando o excepcionalismo}

Recentemente, Thomas Malaby (2007) fez uma argumentação convincente contra o "excepcionalismo" dos game studies. Em parte para merecer a sua existência como uma disciplina de investigação acadêmica, os game studies frequente e sistematicamente exageram na especificidade dos (video)games ao ponto da incomensurabilidade, ou mesmo na diferença ontológica em relação aos outros meios e práticas. Entretanto, assim como com qualquer teoria, uma vez que os laços entre dois diferentes fenômenos foram conceitualmente cortados, torna-se incrivelmente difícil de fazer sentido suas contínuas relações - pense no dualismo mente/corpo como um exemplo disso. Em contraste, a JEFCJ esvazia a idiossincrasia da mídia ficcional $e$ dos jogos ao amarrá-los de volta ao próprio berço da cultura que é o jogar, e ao enfatizar sua união com outras práticas performativas ou de faz-de-conta. Nas palavras de Kendall Walton, "poderemos ver a representacionalidade nas artes como contínua com outras instituições e atividades humanas familiares, em vez de algo único que exige explicações próprias" (WALTON, 1990, p. 7, ).

Em lugar algum essa diferença sobrevalorizada e a pouco apreciada da unidade dos jogos com outras práticas se tornam mais aparente do que naquilo que é frequentemente chamado de "círculo mágico". Cito aqui a já canônica passagem de Huizinga:

Todo jogo se processa e existe no interior de um campo previamente delimitado, de maneira material ou imaginária, deliberada ou espontânea. Tal como não há diferença formal entre o jogo e o culto, do mesmo modo o "lugar sagrado" não pode ser formalmente distinguido do terreno do jogo. A arena, a mesa de jogo, o círculo mágico, o templo, o palco, a tela, o campo de tênis, o tribunal, etc., têm todos a forma e a função de terrenos de jogo, isto é, lugares proibidos, isolados, fechados, sagrados, em cujo interior se respeitam determinadas regras. Todos eles são mundo temporários dentro do mundo habitual, dedicados à prática de uma atividade especial (HUIZINGA, 2001, p. 13).

De acordo com Salen e Zimmerman (2012), os game studies tomaram essa citação como uma robusta articulação de uma separação espacial entre os jogos e a vida cotidiana, e ruminaram sobre sua natureza e permeabilidade desde então: "embora o círculo mágico seja meramente um dos exemplos de uma lista de 'playgrounds' de Huizinga, o termo [círculo mágico] é aqui usado como uma abreviação para a ideia de um lugar especial no tempo e no espaço criado pelo jogo" (SALEN; ZIMMERMAN, 2012, p. 95). 
Em outras palavras, Salen e Zimmerman enfatizam uma relação de figura-fundo, na qual o "jogo" é a figura, e "todo o resto" é o fundo. Entretanto, mesmo uma leitura superficial da passagem acima revela que a figura que Huizinga intentava retratar era uma unidade mais ampla das situações que ele lista como pertencentes ao "jogo", contra o plano de fundo do "mundo cotidiano": "a arena, a mesa de jogo, o círculo mágico, o templo, o palco, a tela, o campo de tênis, o tribunal, etc., têm todos a forma e a função de terrenos de jogo [...]" (HUIZINGA, 2001, p. 13). “[...] não há diferença formal entre o jogo e o culto [...]” (HUIZINGA, 2001, p. 13), e novamente, algumas páginas adiante: "a pista de corrida, o campo de tênis, o tabuleiro de xadrez ou o terreno da amarelinha não se distinguem, formalmente, do templo ou do círculo mágico" (HUIZINGA, 2001, p. 23) ${ }^{12}$.

\subsection{Abordando a licença pragmática compartilhada pelos jogos e-ficção}

Uma importante parte do círculo mágico 'separando' o jogo do resto da vida social é que ele permite que os jogos tenham "consequências negociáveis" (JUUL, 2005, p. 41): o que fazemos no jogo é, normalmente, livre de consequências, embora possamos adicionar consequências ao seu resultado (como por exemplo, apostar dinheiro).

Pesquisadores do campo das artes e da ficção por muito tempo argumentaram que deveria existir uma convenção social ou "contrato" que igualmente separa a ficção da vida cotidiana e a liberta da necessidade de verdade, consequência, confiabilidade e valor econômico. Nos estudos literários, Lejeune (1989) e Umberto Eco (1994) chamam a isso de "pacto ficcional". O pesquisador construtivista da mídia S. J. Schmidt fala de uma "convenção estética" (“Ä-Kovention") e vê os efeitos da mesma em todas as artes (SCHMIDIT, 1980, p. 86, 148). A produção e apreciação da arte e da ficção é considerada livre de questões como a utilidade privada ou pública; elas podem expressar sentimentos que, se expressos em uma carta aberta, seriam tomados como enganações ou difamações.

Resumidamente, os jogos e a ficção compartilham a mesma suspensão pragmática da função e consequência: "é apenas um jogo" ou "é apenas uma história". Enquanto que as definições padrão para o jogo afirmam a existência dessa licença pragmática apenas para os jogos (e as teorias da ficção para as mídias ficcionais), uma compreensão baseada na JEFCJ prontamente reconhece a sua aparência comum e, mais importante, explica isso como uma

\footnotetext{
12 N. do T.: os grifos das três últimas citações foram feitos por Deterding na versão original do trabalho em inglês. Não
} inserimos o indicativo "grifos do autor" após a referência, como é usual, para não atribuir a Huizinga a autoria de tais ênfases. 
derivação do enquadramento do jogar. Essa explicação e funcional (explicando o valor adaptativo do jogar, da ficção e dos jogos), filogenética (explicando sua origem evolutiva), ontogenética (explicando seu desenvolvimento na biografia individual), e é situacional: explicando como essa licença funciona, cognitivamente e socialmente, em um dado jogo, gameplay, e envolvimento com a mídia ficcional. Baseando-se na convenção compartilhada pelo jogar/jogo/ficção, os participantes coordenam comportamentos e interpretações da situação com os quais concordam e reproduzem "o que é que está acontecendo aqui", utilizando pistas metacomunicativas, as quais já foram referidas na teoria ficcional como "sinais de ficcionalidade" (NICKEL-BACON; GROEBEN; SCHREIER, 2000).

\subsection{Abordando o "faz-de-conta" compartilhado da transformação- representação nos jogos e na ficção}

Teorias sobre o "pacto ficcional" não apenas observam a ruptura dos laços pragmáticos da consequência, mas também a ruptura dos laços semânticos do significado. Citando Searle (1975, p. 326, ): "agora o que torna a ficção possível, como sugiro, é um conjunto de convenções extralinguísticas, não semânticas, que rompem com a ligação entre as palavras e o mundo". Essa qualidade semântica é acompanhada por uma disposição experiencial normalmente chamada de "suspensão da crença", a qual nós descrevemos anteriormente como "lúdico": uma aceitação imediata de uma copresença subjuntiva, factual e fictiva, sensível e imaginada. Sherlock Holmes não vive de fato em Baker Street (semanticamente, essa é uma proposição fictiva) - mas, para que possamos nos envolver em um romance de Arthur Conan Doyle, imaginamos um Sherlock Holmes vivendo em Baker Street e não nos deixamos perturbar pelo fato de sabermos que (a) isso não é factualmente verdadeiro, e (b) nós não estamos de fato em Londres observando-o por uma janela, mas sim sentados em um sofá analisando folhas impressas com nossos olhos. Nossa experiência de Sherlock Holmes é uma experiência de "faz-de-conta". Da mesma forma, se um ator numa peça de teatro xinga ou estrangula um outro ator, isso é entendido como sendo apenas um xingamento e um estrangulamento transformado-representado de "faz-de-conta": semanticamente fictivo, experiencialmente 'lúdico'.

Isso é verdade também para os jogos e videogames: se atiramos em alguém em um jogo de tiro em primeira pessoa, isso não é socialmente aceitável apenas por causa de algumas convenções que tratam o jogo como sendo "sem consequência". Não estamos 
realmente atirando em alguém; é apenas uma encenação transformada-representada de atirar em alguém. E o tiro é inofensivo não apenas porque é representado; ele também é uma representação de "faz-de-conta". Esperaríamos que o outro reagisse de forma bem diferente se o nosso controle e nossa tela sabidamente estivessem ligados a um drone em uma zona de guerra realmente atirando em alguém, ou se por acaso a tela mostrasse um documentário que soubéssemos ser um registro de algo acontecido realmente no passado ainda que, em ambos os casos, o que experienciamos em frente a um console se mantivesse sendo uma representação. De modo similar, se dois jogadores de um jogo de boxe no Wii representativamente-transformado começarem a socar um ao outro na frente da televisão e do console gritando ("Tome isso!", “Vou acabar com você!", “Eu te odeio!", etc.), tais situações são tomadas como agressões físicas e verbais não-literais, de "faz-de-conta". Alguém pode dizer que nos jogos o quadro de referência aberto pelas regras adiciona uma outra dimensão experiencial de sentido, copresente ao input de sentido sensorial, imaginativo, factual e fictivo.

O ponto obviamente disputável aqui são os jogos abstratos. Se eu colocar uma peça em um tabuleiro de gamão, certamente este é uma peça real e um tabuleiro real, sem representação, "faz-de-conta" ou imaginação envolvida? Um possível (e um pouco insatisfatório) ponto contrário para se levar em conta é que jogos abstratos dependem do raciocínio simbólico e da comunicação construída sobre um enquadramento compartilhado dessa situação. Colocar um marcador em um tabuleiro não tem nenhum significado do tipo "como-se"; isso se torna significativo apenas na relação do quadro de referências compartilhado pelos jogadores (compreendendo o acordo para se envolver em um jogo como o gamão, o conhecimento comum das regras, sobre como colocar as outras peças, de quem é a vez de jogar, etc.). A colocação da peça representa simbolicamente (e ancora materialmente) uma mudança de estado. Em relação à imaginação, não pretendo me aventurar nas profundezas do problema da fundação dos símbolos aqui. Mas se alguém toma a posição de cognição incorporada, então qualquer significado está fundado em simulações mentais de experiências multimodais, corpóreas e, nesse sentido, imaginativas. Finalmente, penso que poderia ser dito com certa razão que a lacuna experiencial entre o objeto material e o significado simbólico se escancara nos games (e em obras de arte) mais do que em qualquer outro uso de código semiótico mais convencional ou naturalizado, como a fala ou a escrita. Isso é o que Heidegger (1977), em seu ensaio "A origem da obra de arte" (Kunstwerk), pretendeu com a abertura existente entre "Erde" (terra) e "Welt" (mundo) nas 
obras de arte. A tremulação fenomenológica do "lúdico", ou a copresença de material e de significado, é mais imediatamente presente nas obras de arte - e no jogo.

Ainda como foi dito, essa resposta é levemente insatisfatória porque toda comunicação simbólica ou cognição é um "faz-de-conta" nesse sentido frágil e derivativo. Podemos construir um sentido mais robusto? Eu defenderia que não necessariamente precisamos disso para que uma perspectiva JEFCJ seja coerente. A 'questão' não é igualar todas as diferenças entre o jogar, os jogos e a ficção. Certamente, diferentes mídias e diferentes jogos fornecem affordances (GIBSON, 1979) que possibilitam certos usos e experiências em níveis maiores ou menores. Jogos abstratos possibilitam um "faz-de-conta" em nível menor do que, por exemplo, role-playing games (RPGs).

0 ponto da JEFCJ é uma mudança de perspectiva que permita uma melhor compreensão dessas diferentes affordances. Não devemos conceber o faz-de-conta ou a imaginação como condições necessárias para as definições de jogar, ficção ou jogos, mas ao invés, como potenciais ativos ou disposições. Novamente, eles são explicativos, não descritivos: a disposição para o faz-de-conta e para as pistas imaginativas explica a grande facilidade que demonstramos ao tomar mesmo os jogos mais abstratos e incoerentes como trampolins prontos para a imaginação. Os jogos podem sugerir mundos imaginários e fictivos por causa da disposição de jogar. 0 jogar e os jogos infantis, assim como as histórias infantis, são altamente incoerentes para os parâmetros adultos, e ainda assim são solos férteis para mundos ficcionais profundamente envolventes. Como é fácil para uma criança tomar as peças do Banco Imobiliário ${ }^{13}$ e transformar o jogo em uma corrida, com dois peões perseguindo um ao outro nas curvas! Alguma criança consideraria seriamente a imaginação de ser um caubói ou um índio “opcional” (JUUL, 2005, p. 141) para a experiência e a diversão de "Cowboys and Indians"? Mesmo um jogo de habilidade abstrato de "quem acerta a casca que flutua em um rio com uma pedra" pode, inesperadamente, se transformar em pilotos Kamikaze atacando um porta-aviões. E embora uma fenomenologia dos jogos de tabuleiro ainda esteja para ser escrita, qualquer jogador de jogos de tabuleiro rapidamente se lembrará de inúmeras instâncias nas quais elementos do jogo permitiram pequenas imaginações individuais ou compartilhadas, interpretação de papéis, micronarrativas. Fictivas e imaginárias? Certamente. Incoerentes? Seguramente que sim. Em uma expressão: faz-de-conta.

130 jogo originalmente citado pelo autor foi a versão original do Banco Imobiliário, Monopoly. 
A mudança histórica implicada nesta perspectiva é que as indicações de mundos ficcionais e sua incoerência não são nem novas nem específicas dos videogames. Videogames re-inserem ou re-possibilitam aquilo que já está sempre presente no jogar e nos jogos. É mais sensato (e intuitivo, penso eu) enquadrar a realização cultural de jogos abstratos e o desenvolvimento biográfico de práticas de jogo adulto e/ou profissional (TAYLOR, 2006) como uma supressão progressiva do potencial de faz-de-conta e avanço para o primeiro plano das mecânicas de regras. Jogos abstratos culturalmente refinaram e aprimoraram esse aspecto do jogar, da mesma forma como a mídia fictícia refinou e aprimorou as características do faz-de-conta. Historiadores dos mais antigos jogos (supostamente abstratos) que sobreviveram ao tempo nos dizem que estes jogos originalmente simbolizavam alguma outra atividade. Para dar dois exemplos: o jogo de tabuleiro mais antigo que se tem conhecimento, o SENET egípcio, retrata uma jornada espiritual pelo mundo dos mortos (PICCIONE, 1980). E o GO chinês (ou WEI-QUI) representa confrontos de tropas e foi usado para treinamento estratégico desde o início (HALTER, 2006).

\subsection{Reconfigurando as definições de jogo em um quadro de referências mais amplo}

Vamos direcionar nossas observações para um nível mais abstrato. A identidade formal pervasiva do jogo com outras práticas, notada por Huizinga, coloca um sério desafio geral para os game studies. Para o "livro de referência" atualmente em voga, as tentativas de definir os jogos se deram em uma espécie de vácuo, seja completamente por conta própria, ou em comparação a jogar em "casos limítrofes", como os jogos de quebra-cabeças ou de interpretação de papeis (JUUL, 2005; SALEN; ZIMMERMAN, 2004). Eles elaboram listas descritivas de propriedades formais compartilhadas por todos os jogos, em grande parte alheios à questão de saber se elas são suficientes para distinguir os jogos de outras práticas humanas. Um exemplo é que as atuais definições têm dificuldade em diferenciar "jogos" de "esportes" (JUUL, 2005)

Mas na verdade esse é apenas um exemplo: ritual, esporte, arte, mídia ficcional, e jogar são todos concebidos para serem cativantes, são buscados voluntariamente e são fins em si mesmos, modelados se não explicitamente baseados em regras, tranformandorepresentando, 'separados' da vida cotidiana e livres de consequências - como são os jogos. 
Alguns deles foram e ainda são disputas formalizadas: esportes certamente o são, bem como o teatro grego, em seu início, também era uma competição ritualística com premiações (SCHECHNER, 2003), e a poesia começou e permaneceu profundamente enraizada na história de várias culturas como uma batalha de cantores (HUIZINGA, 2001). Será que isso significa que eles eram jogos? Quando um jogo é arte, quando a arte é um jogo - ou algo pode ser os dois ao mesmo tempo? Qual é, então, a diferença entre esporte e jogo?

De forma resumida, as definições de Juul e Salen e Zimmerman (2012) falham ao não incorporar dimensões comparativas - cultura, história, significado, experiência, prática - que poderiam permitir responder tais questionamentos. Ou então as respostas fornecidas são "frágeis", sofismas que nos dizem muito pouco sobre o sentido de um fenômeno X sendo esporte/arte/qualquer coisa ao invés de jogo. Por fim, eles sequer começam a abordar e entender as semelhanças entre todas essas práticas. Uma abordagem JEFCJ, por outro lado, abre um espectro antropológico mais amplo de dimensões comparativas, e articula um fundo comum aos jogos, arte, ritual, etc.

\subsection{Evitando o essencialismo e falsas dicotomias}

Vários problemas emergem da própria natureza formalista das atuais definições de jogo ${ }^{14}$. Elas funcionam trazendo uma lista intensional de propriedades formais cuja extensão, quando aplicada a uma amostra de casos, conteria o que, de alguma forma, seria supostamente o consenso de "parecer bom" ser chamado de jogo - e excluir o que não parece: Tetris, sim; quebra-cabeças, não; jogos de representação de papéis, talvez? (JUUL, 2005; SALEN; ZIMMERMAN, 2004). Pelo menos implicitamente, isso toma forma de uma definição gênero-específica de condições necessárias e suficientes ${ }^{15}$. A definição supostamente permitiria um fácil discernimento diretamente a partir do artefato de jogo, e permitiria chegar a algo pensado como "o jogo em si mesmo" (JUUL, 2005; SALEN; ZIMMERMAN, 2004) - note o essencialismo já implicado nessa frase.

O problema com tais definições formalistas é a sua tendência em essencializar e reificar as categorias que elas mesmo constroem. Elas povoam o zoológico ontológico com entes abstratos, como "arquétipos", "epistemes”, "estruturas”, "jogo", etc., os quais levantam

\footnotetext{
14 Ver Bogost (2006; 2009) para uma crítica geral da ontologia implicada no formalismo inerente aos game studies atuais.

15 O tratamento de Juul $(2005$, p. 43) sobre "casos limítrofes" deixa em aberto o debate sobre se ele tem ou não um caso Wittgensteiniano de modelo de semelhança familiar em mente.
} 
uma dupla questão, que é 'onde' ou em qual plano ontológico esses entes 'existem', e como eles podem afetar o fenômeno observado de onde estão. Além disso, eles exigem uma atribuição definitiva de qualquer ente a uma, e apenas uma, categoria. Algo, ou os elementos de algo, devem 'ser' ou X ou Y, no presente caso: um jogo ou não, uma ficção ou não, ficção ou jogo, etc.

Nos últimos anos, cada vez mais vozes nos game studies articularam a preocupação com a rigidez desse essencialismo implícito e pressionaram por uma conceituação mais fluida, sociológica e não-essencialista, menos dependente do artefato do jogo (JUUL, 2008). Ironicamente, o estudo da ficção (literária) passou por um amadurecimento muito similar, de (1) alegar uma diferença ontológica entre ficção e não-ficção, facilmente discernível das propriedades sintáticas superficiais; (2) relatos analíticos que buscaram uma diferença semântica, ao invés de uma diferença ontológica; (3) perspectivas pragmáticas que afirmam que a distinção ficção/não-ficção está realmente fundamentada em convenções sociais (NICKEL-BACON; GROEBEN; SCHREIER, 2000).

Diversos estudiosos já sugeriram que um dos teóricos da FCJ aqui presentes Ervin Goffman - poderia fornecer uma fundação para uma teoria sociológica dos jogos (PARGMAN; JAKOBSSON, 2008; CONSALVO, 2009) e, de fato, a perspectiva JEFCJ delineada oferece uma definição social e não-essencialista do jogar e da ficção que pode ser igualmente aplicada aos jogos. Se algo 'é' uma peça, um jogo ou uma ficção depende da convenção social compartilhada que ou é individualmente percebida e reproduzida, ou é socialmente aceita e reproduzida pelo(s) participante(s) em uma dada situação. Isso também elimina a falsa dicotomia ficção-ou-jogo ao: (a) mostrar as constantes comuns entre jogos e ficção; e (b) declarar mais uma vez que isso é questão da convenção social em vigor. Nas palavras do historiador de jogos de tabuleiro David Parlett (1999, p. 6): “o quão representacional um jogo é depende do nível em que está sendo jogado e da extensão da imaginação do jogador".

\subsection{Fornecendo poder explicativo}

A terceira desvantagem das atuais concepções formalistas dos jogos é que elas permanecem puramente descritivas. Elas não fornecem uma inclusão teórica explicativa sobre se e por que as categorias que elas constroem não são apenas decisões linguísticas arbitrárias de nomenclatura, por mais úteis que elas sejam para um discurso acadêmico claro. Em outras palavras, elas são ausentes de poder explicativo - em contraste com, 
digamos, taxonomias cladísticas de espécies que supostamente representam significamente relações evolutivas reais de ancestralidade entre as diferentes categorias. Dentro da já delineada perspectiva JEFCJ, categorias como "jogar", "jogo", "mídia ficcional”, "videogame" possuem tal poder explicativo em quatro níveis, já introduzidos:

a) funcional - eles explicam o valor evolucionário adaptativo para o jogar, para a ficção e para os jogos: treinamento de reconhecimento de padrões e cognição social e criatividade comportamental e cognitiva;

b) filogenético - eles explicam as origens evolucionária e cultural das relações entre o jogar, o jogo e a ficção no jogo animal;

c) ontogenético - eles explicam como e quando o jogar, os jogos e a ficção se desenvolvem na biografia de um indivíduo desde o começo de sua infância, e o fingimento do jogar através da socialização;

d) situacional - eles explicam os mecanismos cognitivos e sociais em funcionamento quando brincamos, jogamos um jogo, lemos um livro de ficção, assistimos um filme de ficção, etc. (o acionamento social de enquadramentos, a copresença subjuntiva do faz-de-conta em diversos níveis da experiência).

\subsection{Fornecendo uma história evolucionária e cultural coerente do jogar, dos jogos e da ficção}

Os níveis de explicação filogenético e ontogenético levam diretamente à última vantagem da abordagem JEFCJ. Ela fornece uma base para uma história evolucionária e cultural coerente do jogar, dos jogos e da ficção. Agora, histórias originárias são sempre contestáveis e com razão - as evidências são escassas e altamente suscetíveis à interpretação, e poucas pessoas, talvez ninguém, poderia legitimamente reivindicar possuir uma visão transcultural suficiente. Mas não necessitamos determinar se o jogar, a música poética, o ritual, a história ou os jogos 'vieram primeiro', nem se um deles é 'vertical' em relação ao outro, ou se são todos 'horizontais', ou seja, práticas humanas igualmente primárias (SCHECHNER, 2003). 0 argumento histórico realmente importante a ser feito é que tudo se fundamenta no jogar, que isso se encaixa com as histórias culturais existentes de ficção (RÖSLER, 1980; SCHLAFFER, 1990), e que a multiplicidade de práticas culturalmente diferentes de jogar dos dias atuais, performance, jogos, ficção, já encontradas 
podem ser delineadas como refinamentos culturais específicos, apropriações e transformações das affordances do jogar.

\section{Conclusão}

Este trabalho defendeu que as duas noções teóricas sobre ficção predominantes nos videogames - videogames 'contendo' elementos separados de ficção e jogos, ou a ficção e jogos 'se sobrepondo' em videogames - são malformadas. Não deveríamos conceber jogos e ficção como duas categorias inicialmente separadas que são, depois, recombinadas (acidentalmente ou por necessidade) nos videogames. Ao invés disso, deveríamos entender o jogar como um fundamento comum dos jogos e da ficção.

Em comparação com a posição 'separatista' de Aarseth (2007), esta perspectiva JEFCJ esvazia a forte diferença 'ontológica' entre elementos de origem 'ficcional' e os elementos mais maleáveis e regulamentados nas 'simulações' nos videogames. Ao invés de entender aquilo que é simulado como "diferente [...] do nosso mundo, assim como é diferente da ficção e [...] de outros mundos" (AARSETH, 2007, p. 39, grifos do autor), os mundos das mídias ficcionais, dos jogos, das brincadeiras infantis ou da experiência religiosa são todos entendidos como ontologicamente conjugados enquanto instâncias da encenação do jogar. Todos são um faz-de-conta transformado-representado, liberto de consequência pragmática, potencialmente sugerindo imaginações. Já nos jogos infantis ou em jogos de tabuleiro, os elementos são maleáveis e modelados por regras. Além disso, se algo é mesmo 'ficcional' (no sentido de imaginativamente sugerido) ou 'simulacional' (no sentido de um objeto de regras maleáveis), não é algo ontologicamente predeterminado, mas, pelo menos parcialmente, dependente da minha (ou nossa) encenação e foco interpretativo enquanto estamos envolvidos com o jogo.

No que diz respeito à posição de 'quase-realidade' de Juul (2005), a abordagem JEFCJ sugerida defende que as sugestões de incoerência dos mundos ficcionais não é nada 'novo' aos videogames, mas sim historicamente presente desde o início da infância. A intensidade do envolvimento nesse mundo ficcional certamente depende tanto do que as affordances do artefato de jogo como suporte proporcionam em termos de sinais sensoriais ricos e coerentes, quanto se, e como, o(s) jogador(es) se envolve(m) com ele - como Juul prontamente concorda (2005). A diferença que a abordagem JEFCJ aponta aqui é que o indicativo das imaginações ficcionais não é 'opcionais', ou mesmo 'secundários' a uma 
'natureza' abstrata dos jogos 'como se', mas, ao contrário, uma dimensão sempre copresente da experiência de jogar qualquer jogo. 'Originalmente', os jogos já sempre foram 'ficcionais', no sentido da palavra empregada por Juul.

Repetindo, isso não significa de forma alguma que não existam diferenças significativas entre jogar, mídia ficcional, jogos e videogames. 0 que a abordagem JEFCJ sugere é uma mudança de perspectiva que leva em conta as semelhanças antropológicas mais amplas entre eles, para explicar melhor como eles funcionam e se concretizam, e para melhor articular o que exatamente torna cada meio e prática únicos.

Perceber jogos-e-ficção-como-jogar é observar quais elementos do jogar cada meio respectivo reforça e refina, e quais elementos recuam para o plano de fundo em função disso. Assim como a mídia ficcional transformou os "participantes" do jogar em "apreciadores" passivos (WALTON, 1990) para permitir ao autor o controle necessário à elaboração de uma narrativa e de uma ficção altamente coerente, rica e multifacetada, também os jogos abstratos silenciaram o potencial de faz-de-conta do jogar para impedir uma distração das alegrias do raciocínio estratégico e dos conflitos competitivos.

Na introdução, caracterizei a teoria popular "extensionista" dos videogames que entende os mesmos como sendo "ficção + interatividade". Entendendo jogos e ficção como um jogar, podemos reescrever um pouco essa fórmula: a ficção, nesses termos, é "jogar interatividade + pistas imaginárias ricas e coerentes"; os jogos são "jogar + regras explícitas"; jogos abstratos são "jogar + regras explícitas - pistas imaginárias ricas e coerentes"; e muitos dos videogames atuais são "jogar + regras explícitas + pistas imaginárias ricas e coerentes". Em certo sentido, os videogames realizam o potencial do jogar como nem os jogos nem a mídia ficcional fizeram antes. A aposta está lançada para saber qual outro elemento do jogar deve retroceder em contrapartida.

\section{Referências}

AARSETH, Espen. Cybertext: Perspectives on Ergodic Literature. Baltimore, Maryland: Johns Hopkins University Press, 1997.

AARSETH, Espen. Doors and Perception: Fiction vs. Simulation in Games. Intermédialités: histoire et théorie des arts, des lettres et des techniques, v. 9, p. 35-44, 2007. https://id.erudit.org/iderudit/1005528ar 
ALLAND, Alexander. The Artistic Animal. New York: Knopf Doubleday Publishing Group, 1977.

BATESON, Gregory. Mind and nature: a necessary unity. Nova York: E. P. Dutton, 1979.

BATESON, Gregory. Steps to an ecology of mind: collected essays in anthropology, psychiatry, evolution and epistemology. Londres: University of Chicago Press, 2000.

BOGOST, Ian. Unit operations: an approach to videogame criticism. Cambridge: The MIT Press, 2006.

BOGOST, Ian. Video games are a mess. In: DIGRA, 2009, Uxbridge. Proceedings [...]. Uxbridge: Brunel University, 2009.

BOYD, Brian. On the origin of stories. Cambridge: The Belknap Press of Harvard University Press, 2009.

CONSALVO, Mia. There is no Magic Circle. Games and Culture, v. 4, n. 4, pp. 408-417, 2009. https://doi.org/10.1177\%2F1555412009343575

DROOGERS, André. Methodological ludism beyond religionism and reductionism. In: A. van Harskamp (org.), Conficts in social science. London e New York: Routledge, p. 44-67, 1996.

ECO, Umberto. Six Walks in the Fictional Woods. Cambridge, Massachusetts: Harvard University Press, 1989

FRASCA, Gonzalo. Ludologists love stories, too. In: Digra proceedings, Utrecht, 2003.

GIBSON, James. The ecological approach to visual perception. Boston: Houghton Mifflins, 1979.

GOFFMAN, Erving. Os quadros da experiência social: uma perspectiva de análise. Petrópolis: Vozes, 2012.

HALTER, Ed. From Sun Tzu to XBox: War and Video Games. New York: PublicAffairs, 2006

HEIDEGGER, Martin. A origem da obra de arte. Lisboa: Edições 70, 1977.

HUIZINGA, Johan. Homo ludens: o jogo como elemento da cultura. 5a ed. São Paulo: Perspectiva, 2001.

JUUL, Jesper. Half-real: video games between real rules and fictional worlds. [Kindle Version]. Cambridge: The MIT Press 2005.

JUUL, Jesper. The Magic Circle and the Puzzle Piece. In GÜNZEL, Stephan, LIEBE, Michael e MERSCH, Dieter (orgs.): Conference Proceedings of the Philosophy of Computer Games 2008. Potsdam: Potsdam University Press 2008.

LEJEUNE, Philippe. On Autobiography. Minneapolis: University of Minnesota Press, 1989 
MALABY, Thomas Beyond Play: A New Approach to Games. Games and Culture, v. 2, p. 95 113, 2007. https://doi.org/10.1177/1555412007299434

MURRAY, Janet $\mathrm{H}$. Toward a cultural theory of gaming: digital games and the co-evolution of media, mind, and culture. Popular Communication, v. 4, n. 3, p. 185-202, 2006.

NICKEL-BACON, Irmgard, GROEBEN, Norbert e SCHREIER, Margrit. (2000). Fiktionssignale pragmatisch: Ein medienübergreifendes Modell zur Unterscheidung von Fiktion(en) und Realität(en). Poetica, v. 32, pp. 267-299, 2000.

NIEDING, Gerhild e OHLER, Peter. An evolutionary perspective on entertainment. in BRYANT, Jennings e VORDERER, Peter (orgs) Playing Computer Games: Motives, Responses, and Consequences. New York: Lawrence Erlbaum, p. 101-113 2006.

PARGMAN, Daniel e JAKOBSSON, Peter. Do you believe in magic? Computer games in everyday life. European Journal of Cultural Studies, v. 11, pp. 225-244, 2008. $10.1177 / 1367549407088335$.

PARLETT, David. Oxford History of Board Games. Oxford: Oxford University Press, 1999. PICCIONE, Peter. In Search of the Meaning of Senet. Archaeology v. 33, n.4, pp. 55-58, 1980. RÖSLER, Wolfgang. Die Entdeckung der Fiktionalität in der Antike, Poetica, v.12, pp. 283$319,1980$.

RYAN, Marie-Laure. Fictional Worlds in the Digital Age. in Susan Schreibman e Ray Siemens (orgs). A Companion to Digital Literary Studies. Oxford: Blackwell, 2008. http://www.digitalhumanities.org/companionDLS/

SALEN, Katie; ZIMMERMAN, Eric. Regras do jogo: fundamentos do design de jogos. Vol.1. São Paulo: Blucher, 2012.

SCHECHNER, Richard. Performance Theory. London: Routledge, 2003.

SCHMIDT, Siegfried J Fictionality in literary and non-literary discourse. Topics in Catalysis v. 9, n. 5-6, 1980, p. 525-546

SCHILLER, Friedrich. Educação Estética do Homem. São Paulo: Iluminuras, 1989.

SCHLAFFER, Heinz. Poesie und Wissen: Die Entstehung des ästhetischen Bewußtseins und der philologischen Erkenntnis. Frankfurt am Main: Suhrkamp, 1990

SEARLE, John R. The logical status of fictional discourse. New Literary History, v. 6, n. 2, p. 319-332, 1975.

SICART, Miguel. Play matters. Cambridge: MIT Press, 2014.

SUTTON-SMITH, Brian. The Ambiguity of Play. Cambridge, Massachusetts: Harvard University Press, 2009. 
TAYLOR, T.L. Play between worlds. Exploring online game culture. Cambridge, MA; London: MIT Press. 2006

WALTON, K. L. Mimesis as make-believe: on the foundations of the representational arts. Cambridge: Harvard University Press, 1990.

\title{
Fiction as play: reassessing the relation of games, play, and fiction
}

\begin{abstract}
Game studies have long debated how to relate fictional and game elements within video games. This article proposes that many of the conceptual puzzles in this debate can be resolved if games and fiction are not treated as separate, but as specific formalisations of the same underlying phenomenon, play. The article presents five theoretical proponents of this games-andfiction-as-play (GAFAP) approach, according to which games and fiction bear more similarities than differences. It draws out the shared tenets and advantages of such a GAFAP approach, and how it helps explain both the commonalities and differences of fiction and games.
\end{abstract}

\section{Keywords}

Games. Play. Fiction. Pragmatics. Frames. 